\title{
Brain temperature and brain metabolism measurements: Rapid in vivo markers of mood i.e. mania or depressive disorders
}

\author{
Francesco Crespi* \\ Biology Dept. GSK Verona, Italy
}

\section{Background}

Recently, scientific interest has increased upon the influence of temperature in the physiopathology of various neurodegenerative and psychiatric disorders. It has been shown that lowering core body and brain temperature has been shown to be beneficial for multiple sclerosis, cardiovascular accidents, traumatic brain injuries and myocardial infarction $[1,2]$.

In 2005 Salerian and Saleri have proposed that a relatively minor alteration in core body or brain temperature may be of significant therapeutic benefit in combating neurodegenerative disorders and prolonging lifespan. In addition, they postulate that brain temperature may rise with mania and fall with depression and propose that therapeutic manipulation of brain temperature may represent a key mechanism in the treatment of mood disorders.

Indeed, studies with rats suggest that lithium increases brain cholinergic activity and heat shock proteins, both resulting in hypothermia [3,4]. Similarly, other neuroleptics such as clozapine, olanzapine and risperdal produce a dose-dependent drop of colon temperature in adult male Wistar rats [5], as well as chlorpromazine induces a drop-in colon temperature in rats [6].

In humans, neuroleptics, with a few exceptions, seem to be hypothermic, i.e. haloperidol, olanzapine and risperdal reduce axillary temperature while clozapine decreases core body temperature and displays a linear relationship between the degree of hypothermia and improvement of psychosis. Overall, it appears that lithium and neuroleptics are hytpothermic and that neuroleptic-induced hypothermia is associated with amelioration of psychosis in schizophrenic patients [7]. Accordingly, clinical manifestations such as transient and reversible psychosis with auditory and visual hallucinations that appear when core body temperature rises above 39 ${ }^{\circ} \mathrm{C}$ disappear after core body temperature normalizes [8].

On the other hand, it appears that many antidepressants currently in clinical use (i.e. sibutramine, duloxetine, butryptiline, protryptiline, nortryptiline]) have marked thermogenic properties in rodents $[9,10]$. In particular, bupropion, a dopamine/norepinephrine reuptake inhibitor, increases brain and colon temperature in rats [11]. The studies on the effects of antidepressants on humans have been contradictory; yet there is one study that suggests chronic administration of antidepressants elevates tympanic membrane temperature [12]. In addition, it is interesting that patients with moderate hypothermia experience bradycardia and hypotension (following early and brief tachycardia and hypertension) as well as progressive depression of mental functions starting with apathy, psychomotor retardation, and silence [1].

\section{Proposal}

On the basis of the above background, oxymetry ( $\mathrm{pO}_{2}$ and blood flow (BF) together with temperature measurements (Temp-oxymetry) could be used as rapid screener of chemicals with "antidep" (or neuroleptic) capacities [13-19].

\section{Program}

Validation and implementation of Temp response of the Tempoxymetric probe inserted in discrete brain areas of anaesthetized rats via:

a) $\mathrm{O}_{2}$ or $\mathrm{CO}_{2}$ (various conc.) challenges and parallel analysis of $\mathrm{pO}_{2}, \mathrm{BF}$ and brain Temp changes;

for instance, $2,5 \%, 5 \%$ and $7.5 \% \mathrm{CO} 2$ challenge are successfully applicable to the same animal (see Crespi 2013 and also see Figure 1) therefore these experiments can be performed rapidly i.e. within 5 days $(n=5)$.

b) Controlled changes of body temperature i.e. by means of the "heating pad" and consequent analysis of brain Temp changes;

Again, here experiments should be performed rapidly when obtaining good corresponding parameters between "heating pad" temperature-controlled increases [or decreases] and rat body temperature.

In particular, Salerian claims that small alterations of body temperature (i.e. $1^{\circ} \mathrm{C}$ degree) may significantly alter biochemical reactions resulting in mood modification [2,14]. Thus, in our experiments changes of 1,2 (maximum 3 ?) ${ }^{\circ} \mathrm{C}$ degrees of body temperature could be applied, then the putative influence of such body temperature changes (i.e. increasing or decreasing) can be monitored upon brain Temp as well $\mathrm{pO}_{2}$ and $\mathrm{BF}$ levels. Again, this study may need a couple of weeks to be perfomed i.e. $n=5$ for each degree change.

c) Test with known hypothermic [i.e. haloperidol, olanzapine] or thermogenic [i.e. bupropion] compounds.

${ }^{\star}$ Correspondence to: Francesco Crespi, Biology Dept. GSK Verona, Italy, E-mail fm.crespi@libero.it

Received: August 19, 2018; Accepted: August 24, 2018; Published: August 31, 2018 


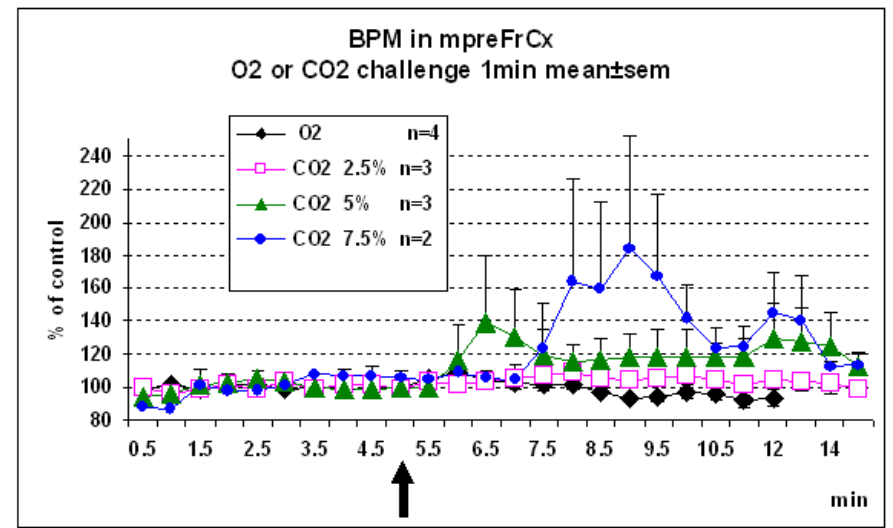

Figure 1. Preliminary data showing the effect of the challenge (arrow) with pure Oxygen $\left(\mathrm{O}_{2}\right)$ or carbon dioxide $\left(\mathrm{CO}_{2}\right)$ at different doses during 1 min upon blood pressure (BPM) monitored in rat medial prefrontal cortex (mpreFrCx) Similar effects of $\mathrm{CO} 2$ challenge are observed upon BF and Temperature [15]

For instance, experiments to measure Temp changes could be performed with a hypothermic i.e haloperidol or a thermogenic i.e. bupropion compound within 20 working days ( $\mathrm{n}=5$ each compound $+\mathrm{n}=5$ controls). Parallel oxymetric measurements of $\mathrm{pO}_{2}$ and blood flow will correlate the metabolic state of the brain region studied.

d) Test with antidepressants such as DOV (TRUI) versus citalopram (for serotonin); reboxetine (for noradrenaline), GBR12909 (for dopamine) to set up METABOLIC FINGERPRINTS OF ANTIDEPRESSANTS [doses obtained from EEG studies] to support and finalize the putative correlation metabolism-depression.

$\mathrm{N}=5$ each group i.e. five weeks work (4 treated, 1 control).

Successful data could be supportive of further experiments achievable in conscious rats prepared for Temp-oxymetry [i.e. in frontal cortex] that will be monitored while undergoing acute (i.e. tonic immobility) or chronic (i.e. chronic mild stress) behavioural models used for the characterisation of antidepressants. Each one of these tests could be performed in two groups rats treated with vehicle (control group) or with thermogenic [i.e. bupropion] compounds.

Successful data would then suggest that temperature change may represent a critical mechanism in the patho-physiology of mood disorders and may promise an avenue for therapeutic exploitation, for instance, treatments also inducing hyperthermia may help in depression.

\section{References}

1. Blatteis C (1998) Physiology and pathophysiology of temperature and regulation. World Scientific Printers, Singapore
2. Salerian AJ, Saleri NG, Salerian JA (2008) Brain temperature may influence mood: a hypothesis. Med Hypotheses 70: 497-500. [Crossref]

3. Lerer B. (1985) Studies on the role of brain cholinergic systems in the therapeutic mechanisms and adverse effects of ECT and lithium. Biol Psychiatry 121: 20-40. [Crossref]

4. Ren M, Senatorov V, Chen R, Chuang D (2003) Post-insult treatment with lithium reduces brain damage and facilitates neurological recovery in rat ischemia/reperfusion model. Mol Neurobiol Sect 100:6210-6215.

5. Oerther S, Ahlenius S (2000) Atypical Antipsychotics and Dopamine D1 Receptor Agonism: An In Vivo Experimental Study Using Core Temperature Measurements in the Rat. J Pharmacol Experimental Therap 292: 731-736.

6. Kollias J, Bullard RW (1964) The influence of chlorpromazine on physical and chemical mechanisms of temperature regulation in the rat. J Pharmacol Exp Ther. 145 373-381. [Crossref]

7. Heh W, Herrera J, DeMet E (1988) Neuroleptic induced hypothermia associated with amelioration of psychosis in schizophrenia. Neuropsychopharmacology 1: 149-156. [Crossref]

8. Okumura A, Nakano T, Fukumoto Y, Higuchi K, Kamiya H, et al. (2005) Delirious behavior in children with influenza: its clinical features and EEG findings. Brain Dev 27: 271-274. [Crossref]

9. Liu YL, Connoley IP, Heal DJ, Stock MJ (2004) Pharmacological characterisation of the thermogenic effect of bupropion. Eur J Pharmacol 498: 219-225. [Crossref]

10. Dulloo AG, Miller DS (1987) Screening of drugs for thermogenic anti-obesity properties: antidepressants. Ann Nutr Metab 31: 69-80. [Crossref]

11. Hasegawa H, Meeusen R, Sarre S, Diltoer M, Piacentini MF, et al. (2005) Acute dopamine/norepinephrine reuptake inhibition increases brain and core temperature in rats. J Appl Physiol 99: 1397-1401. [Crossref]

12. Kudoh A, Tkase H, Takazawa T. (2003) Chronic treatment with antidepressants decreases intraoperative core hypothermia. Anaesth Analg 97: 275-279. [Crossref]

13. Salerian AJ (2010) Thermodynamic laws apply to brain function. Med Hypotheses 74: 270-274. [Crossref]

14. Battisti-Charbonney A, Fisher J, Duffin J (2011) The cerebrovascular response to carbon dioxide in humans. J Physiol 589: 3039-3048. [Crossref]

15. Crespi F (2013) In vivo oxymetric analysis of mild hypercapnia upon cerebral oxygen, temperature and blood flow: markers of mood as proposed by concomitant bupropion challenge and electrochemical analysis?" Exp Brain Res 230: 597-604. [Crossref]

16. Nomikos GC, Damsma G, Wenkstern D (1989) Acute effects of bupropion on extracellular dopamine concentrations in rat striatum and nucleus accumbens studied by in vivo microdialysis. Neuropsychopharmacology 2: 273-279. [Crossref]

17. Nomikos GC, Damsma G, Wenkstern D (1992) Effects of chronic bupropion on interstitial concentrations of dopamine in rat nucleus accumbens and striatum. Neuropsychopharmacology 7: 7-14. [Crossref]

18. Salerian AJ, Saleri NG (2005) Cooler biologically compatible core body temperatures may prolong longevity and combat neurodegenerative disorders. Med Hypotheses 66: 636-642. [Crossref]

19. Van der Bell R, Çaliskan M, van Hulst RA, et al. (2017) Blood Pressure Increase during Oxygen Supplementation in Chronic Kidney Disease Patients Is Mediated by Vasoconstriction Independent of Baroreflex Function. Front Physiol 8: 186. [Crossref]

Copyright: (C2018 Crespi F. This is an open-access article distributed under the terms of the Creative Commons Attribution License, which permits unrestricted use, distribution, and reproduction in any medium, provided the original author and source are credited. 